\title{
In Vivo Regulation of Human Mononuclear Leukocyte 3-Hydroxy-3-Methylglutaryl Coenzyme A Reductase Decreased Enzyme Catalytic Efficiency in Familial Hypercholesterolemia
}

Peter W. Stacpoole," Donna M. Bridge," Idania M. Alvarez," Ronald B. Goldberg,; and H. James Harwood, Jr.*

*Departments of Medicine (Division of Endocrinology and Metabolism) and Pharmacology, University of Florida, College of Medicine, Gainesville, Florida 32610; and $\ddagger$ Department of Medicine (Division of Endocrinology), University of Miami,

School of Medicine, Miami, Florida 33101

\begin{abstract}
3-Hydroxy-3-methylglutaryl coenzyme A reductase (HMG CoA reductase) controls the rate of cholesterol biosynthesis and is itself modulated through feedback suppression by internalized low density lipoprotein (LDL) cholesterol. We measured HMG CoA reductase protein concentration and microsomal enzyme activity in freshly isolated mononuclear leukocytes from normal individuals and patients with heterozygous or homozygous familial hypercholesterolemia (FH). Reductase protein concentration was similar in normal and heterozygous subjects, but was over twofold elevated in patients with homozygous FH. Reductase protein concentration was inversely related to LDL receptor status. Total activity and catalytic efficiency of reductase, however, were decreased in heterozygous and homozygous FH patients. The decrease in catalytic efficiency was not due to enzyme phosphorylation or thiol-disulfide formation. Reduction of plasma cholesterol concentration over $2 \mathrm{~h}$ by plasmapheresis increased reductase activity, the degree of which was directly proportional to the LDL-receptor status of the subjects.

Decreased HMG CoA reductase activity and catalytic efficiency in mononuclear leukocytes and perhaps other cells in FH may represent a fundamental abnormality in the regulation of this enzyme independent of that induced by the LDL-receptor defect and may provide new insight into the control of cholesterol metabolism in FH.
\end{abstract}

\section{Introduction}

Under normal circumstances most human tissues are thought to derive most of their cholesterol from circulating lipoproteins, rather than from intracellular biosynthesis (1). In healthy humans increased cellular demand for cholesterol stimulates the synthesis of cell surface receptors that bind and internalize predominantly low density lipoprotein (LDL) (2). Lipopro-

Dr. Harwood's present address is Atherosclerosis Section, Dept. of Metabolic Diseases, Pfizer Central Research, Pfizer Inc., Eastern Point Rd., Groton, CT 06340. Address correspondence to Dr. Stacpoole at the Division of Endocrinology and Metabolism, University of Florida, College of Medicine, Gainesville, FL 32610.

Received for publication 8 January 1987 and in revised form 27 May 1987.

J. Clin. Invest.

(c) The American Society for Clinical Investigation, Inc.

$0021-9738 / 87 / 11 / 1401 / 08 \quad \$ 2.00$

Volume 80, November 1987, 1401-1408 tein-derived cholesterol is not only used for diverse cellular functions but also inhibits the activity of 3-hydroxy-3-methylglutaryl coenzyme A reductase (HMG CoA reductase), ${ }^{1}$ the endoplasmic reticulum enzyme that catalyzes the rate-determining step in cholesterol formation (3). Thus, circulating cholesterol levels and endogenous cholesterol production are, in large part, coordinately controlled by receptor-mediated uptake of $\operatorname{LDL}(4,5)$.

In familial hypercholesterolemia (FH), however, the regulatory mechanisms ensuring cholesterol homeostasis are perturbed. In this dominantly transmitted condition, plasma cholesterol levels are increased and lead to premature atherosclerosis (6). The etiology of the disease is considered to be an inherited abnormality in the uptake and metabolism of lipoprotein cholesterol. Patients heterozygous for $\mathrm{FH}$ are thought to possess only about half the normal number of functioning LDL receptors, while homozygous individuals exhibit little or no receptor activity (6). Studies with culture fibroblasts suggest that, despite their reduced receptor status, cells from patients with heterozygous FH internalize sufficient lipoprotein cholesterol to maintain HMG CoA reductase in its normally suppressed state (7). In contrast, it is presumed that the defect in receptor activity in homozygous subjects is so severe that feedback regulation of cholesterol biosynthesis by LDL is virtually absent and HMG CoA reductase activity is abnormally high $(6,7)$.

We recently described sensitive and specific techniques for determining HMG CoA reductase activity (8) and protein concentration (9) in microsomal fractions from freshly isolated human mononuclear leukocytes. Studies in healthy human subjects (10) indicate that mononuclear leukocyte HMG CoA reductase activity responds to various nutritional and pharmacologic perturbations in a manner similar to that of the enzyme isolated from animal intestine or liver (11). In the present investigation we measured the activity and protein content of HMG CoA reductase in mononuclear cells obtained from healthy adults and patients with heterozygous or homozygous FH. We found that enzyme protein concentration was elevated in cells from individuals with homozygous FH whereas both enzyme activity and catalytic efficiency were markedly decreased in cells derived from either heterozygous or homozygous patients. In addition, rapid reduction of plasma cholesterol levels by plasmapheresis induced a prompt increase in HMG CoA reductase activity that was proportional to the LDL-receptor status of the subject.

1. Abbreviations used in this paper: $\mathrm{FH}$, familial hypercholesterolemia; HMG-CoA reductase, 3-hydroxy-3-methylglutaryl coenzyme A reductase; TEDK, Tris, EDTA, dithiothreitol, and potassium chloride. 


\section{Methods}

Subjects. This investigation was approved by the Institutional Review Board of Shands Hospital, Gainesville, FL. 31 normocholesterolemic males, aged 20-66 yr, 13 heterozygous FH patients (five males), aged 14-66 yr, and 12 homozygous FH patients (seven males), aged 6-52 yr, participated. Mean age, serum lipid, and lipoprotein values for each group are summarized in Table I. Heterozygous FH was diagnosed by documenting recurrent serum total and LDL-cholesterol levels greater than the 95th percentile, based on age and sex (12), together with a family history of hypercholesterolemia consistent with an autosomal dominant mode of transmission. Heterozygous patients also had a personal history of premature ischemic heart disease. One patient received cholestyramine and one control subject took propranalol during the investigation. No other participant received medicines known to alter lipid metabolism.

The 12 patients homozygous for $\mathrm{FH}$ were diagnosed on the basis of serum total and LDL-cholesterol levels at least 2.5 -fold above the 95 th percentile, appearance of xanthomas before adolescence, hypercholesterolemia in both parents, and in eight subjects, analysis of their LDLreceptor status in cultured fibroblasts (determined by Drs. M. S. Brown and J. L. Goldstein, Dallas, TX). Four patients were LDL-receptornegative ( $<2 \%$ normal receptor activity) and four were LDL-receptor-defective (5-20\% normal activity). The remaining four homozygous FH patients in whom receptor studies were not performed fulfilled all other criteria for homozygous disease. Ethnic origin and geographic location of the homozygous subjects were diverse. One patient was from Florida, three were from Tennessee, four were from Ontario, Canada, and four were from Johannesburg, South Africa. Patients were of Italian, German, French, Ghanian, and Afrikaner descent.

Chemicals. Gelatin, Tween-20, 4-chloro-1-naphtol, and electrophoresis-grade Tris, were from Bio-Rad Laboratories (Richmond, CA). Hydrogen peroxide, alkaline phosphatase, and glucose-6-phosphate dehydrogenase were from Sigma Chemical Co. (St. Louis, MO). $\mathrm{NADP}^{+}$, glucose-6-phosphate, and dithiothreitol were from U. S. Biochemical Corp. (Cleveland, $\mathrm{OH}$ ). Biotinylated donkey anti-rabbit immunoglobulin (cat. No. RPN 1004), streptavidin, and horseradish peroxidase conjugate (cat. No. RPN 1231) were from Amersham Corp. (Arlington Heights, IL). [3-14 C]HMG-CoA $(57 \mathrm{mCi} / \mathrm{mmol})$ and [5- $\left.{ }^{3} \mathrm{H}\right]$ mevalonolactone $(24 \mathrm{Ci} / \mathrm{mmol})$ were from New England $\mathrm{Nu}$ clear (Boston, MA). Polyclonal, monospecific anti-rat liver HMGCoA reductase antiserum (13) was kindly supplied by Dr. G. C. Ness (University of South Florida, Tampa, FL). All other materials were from previously listed sources $(14,15)$.

Solutions. 10 times Hanks' balanced salts solution contained 80 $\mathrm{g} /$ liter $\mathrm{NaCl}, 4 \mathrm{~g} /$ liter $\mathrm{KCl}, 10 \mathrm{~g} /$ liter glucose, $600 \mathrm{mg} /$ liter $\mathrm{KH}_{2} \mathrm{PO}_{4}$, $475 \mathrm{mg} /$ liter $\mathrm{Na}_{2} \mathrm{HPO}_{4}$, and $170 \mathrm{mg} /$ liter phenol red (pH 7.4). TEDK buffer contained $50 \mathrm{mM}$ Tris (pH 7.5), $1.0 \mathrm{mM}$ EDTA, $5.0 \mathrm{mM}$ dithiothreitol, and $70 \mathrm{mM} \mathrm{KCl}$.

\section{Isolation of peripheral blood mononuclear leukocytes and microsomes}

Mononuclear leukocytes were obtained from 40-ml blood samples by density gradient centrifugation over Histopaque 1077 and leukocyte microsomes were isolated as previously described (15). Mononuclear preparations obtained in this manner contained $>96 \%$ viable cells and consisted of $77 \%$ lymphocytes and $23 \%$ monocytes. Interassay variation of the lymphocyte/monocyte ratio was $1.3 \%$. Plasmapheresis was conducted using an IBM 2997 blood cell separator. A single-stage two-channel system was used to simultaneously collect white cells and plasma. Separation of leukocytes from plasma was accomplished by placing the interphase at the white cell collection port. A 4-liter plasma exchange was conducted at a flow rate of $60 \mathrm{ml} / \mathrm{min}$ and a centrifuge speed of $1,600 \mathrm{rpm}$. The coagulant used was acid citrate dextrose $A$ and the replacement fluid was $5 \%$ human albumin and normal saline. Separation of monocytes from lymphocytes was conducted as previously described (15). By this method, monocyte-enriched prepara- tions were $\sim 75 \%$ pure, with contaminating cells being almost exclusively lymphocytes. Lymphocyte-enriched populations were $\sim 95 \%$ homogeneous and included $\sim 3 \%$ monocytes and $\sim 2 \%$ granulocytes.

\section{Measurement of HMG CoA reductase activity}

Mononuclear leukocyte microsomal HMG CoA reductase activity was measured as reported previously (15), except that the specific activity of $\left[3-{ }^{14} \mathrm{C}\right] \mathrm{HMG} \mathrm{CoA}$ used was $30 \mathrm{cpm} / \mathrm{pmol} .68 \mathrm{mM}$ EDTA was included in all incubations to prevent conversion of mevalonate to phosphomevalonate. HMG CoA reductase activity was determined in $150 \mu \mathrm{g}$ of microsomal protein and is expressed as picomoles mevalonate formed per minute incubation at $37^{\circ} \mathrm{C} / \mathrm{mg}$ microsomal protein. Under these conditions, HGM CoA reductase is fully activated through dephosphorylation (16).

\section{Measurement of HMG CoA reductase protein concentration}

A portion of each microsomal pellet used for determination of enzyme activity was retained for measurement of reductase protein concentration by a recently developed solid-phase enzyme immunoassay (9). Mononuclear leukocyte HMG CoA reductase protein concentration is expressed as micrograms immunoreactive protein per milligram microsomal protein. Enzyme catalytic efficiency was calculated by dividing enzyme activity by enzyme protein concentration and is expressed as picomoles per minute per milligram immunoreactive protein.

\section{Measurement of microsomal protein concentration}

Protein content was determined by the method of Bradford (17), using bovine serum albumin as the standard.

\section{Lipid and lipoprotein analyses}

Blood was obtained for serum lipid and lipoprotein determinations at the same time samples were collected for mononuclear leukocyte HMG CoA reductase activity. Serum total cholesterol and triglycerides were measured by standard, automated procedures. High density lipoprotein (HDL) cholesterol was determined by heparin-manganese precipitation (18). LDL cholesterol and very low density lipoprotein (VLDL) cholesterol concentrations were calculated by the method of Friedewald et al. (19).

\section{Statistical analysis}

The unpaired Student's $t$ test was used to determine statistical significance between the mean HMG CoA reductase values in the normal and $\mathrm{FH}$ populations.

\section{Results}

Serum lipoprotein levels. Mean age, serum lipid, and lipoprotein values for normal subjects and patients with heterozygous or homozygous FH are presented in Table I. Total and LDLcholesterol concentrations were approximately twofold elevated in 13 patients with heterozygous $\mathrm{FH}$ and approximately fourfold elevated in 12 subjects with homozygous disease. HDL-cholesterol levels were normal in heterozygous individuals, but were significantly decreased in homozygous patients $(P<0.05)$.

$H M G$ CoA reductase protein concentration. Table II summarizes data on the concentration of immunoreactive HMG $\mathrm{CoA}$ reductase protein present in mononuclear leukocytes obtained in the basal state from healthy subjects and FH patients. In heterozygous FH patients, whose cells are presumed to possess approximately one-half the normal number of functional LDL receptors (1), the mean $\mathrm{HMG}$ CoA reductase protein concentration was only slightly greater than that observed in healthy subjects $(P>0.05)$. In contrast, mononuclear leukocyte HMG CoA reductase protein levels were approximately 
Table I. Serum Lipid and Lipoprotein Concentrations in Normal Individuals and Patients with FH

\begin{tabular}{lllllllr}
\hline Diagnosis & $n$ & Age & Total cholesterol & VLDL cholesterol & LDL cholesterol & HDL cholesterol & Triglycerides \\
\hline & & $y r$ & & $m g / d l$ & & \\
Normal & 31 & $39 \pm 3$ & $194 \pm 9$ & $18 \pm 1$ & $129 \pm 7$ & $55 \pm 2$ & $92 \pm 7$ \\
Heterozygous FH & 13 & $40 \pm 5$ & $388 \pm 31$ & $25 \pm 2$ & $310 \pm 30$ & $51 \pm 4$ & $125 \pm 11$ \\
Homozygous FH & 12 & $23 \pm 4$ & $582 \pm 33$ & $26 \pm 7$ & $529 \pm 36$ & $28 \pm 2$ & $136 \pm 35$ \\
\hline
\end{tabular}

Serum from $7 \mathrm{ml}$ of blood was obtained from 31 healthy normocholesterolemic subjects, 13 patients with heterozygous FH, and 12 patients with homozygous FH after an 11-14-h overnight fast. Serum lipid and lipoprotein concentrations were measured as described in Methods.

twofold above normal in patients with homozygous FH $(P$ $<0.001)$. In patients with receptor-defective disease $(n=4)$, the HMG CoA reductase protein level was $149 \%$ of normal, while in receptor-negative individuals $(n=4)$, enzyme protein concentration was increased to $277 \%$ of normal. When the concentration of $\mathrm{HMG}$ CoA reductase protein was expressed as a function of the log of the LDL-receptor status, a negative linear correlation was observed (Fig. 1). Thus, as predicted by the LDL-receptor hypothesis (1), as the ability to internalize LDL cholesterol is reduced, feedback suppression of HMG CoA reductase is also decreased and enzyme protein concentration rises.

HMG CoA reductase activity and catalytic efficiency. Fig. 2 depicts basal microsomal HMG CoA reductase activity measured in freshly isolated mononuclear leukocytes from normal males and patients with heterozygous or homozygous FH. Enzyme activity in cells from normal subjects averaged $10.3 \pm 0.8$ $\mathrm{pmol} / \mathrm{min}$ per $\mathrm{mg}$ and ranged from $\sim 4$ to $\sim 22 \mathrm{pmol} / \mathrm{min}$ per mg. Mean HMG-CoA reductase activity was significantly decreased $(54 \% ; P<0.001)$ in both heterozygous and homozygous FH patients. One of the highest enzyme levels $(6.5 \pm 0.2$ $\mathrm{pmol} / \mathrm{min}$ per $\mathrm{mg}$ ) measured in the heterozygous group was in the subject receiving cholestyramine, a drug known to increase reductase activity in animal leukocytes (20) and other tissues (21). Since enzyme protein levels were normal in mononuclear leukocytes from heterozygous individuals (Table II), the diminished HMG CoA reductase activity observed in these subjects reflects a $70 \%$ decrease in the catalytic efficiency (i.e., specific activity) of the enzyme molecule (Table II). An even greater reduction in enzyme catalytic efficiency ( $80 \%$ below normal) was noted in homozygous subjects (Table II), since mean HMG CoA reductase protein concentration was increased in these patients. Thus, the degree of suppression of HMG CoA reductase activity and catalytic efficiency was nearly identical in heterozygous and homozygous $\mathrm{FH}$ patients and did not correlate with either LDL-receptor status or serum LDL-cholesterol concentration (refer to Table I and Fig. 1).

Effects of phosphoprotein phosphatase and dithiothreitol. The catalytic activity of leukocyte HMG CoA reductase is modulated by reversible phosphorylation, in which the unphosphorylated enzyme is active (22), and by reversible thioldisulfide formation, in which the reduced enzyme is active (23). The method for isolating leukocyte microsomes (15) fully activates HMG CoA reductase with respect to phosphorylation and thiol-disulfide reduction. No further increase in enzyme activity was found when leukocyte microsomes were incubated in the presence of phosphoprotein phosphatase or $20 \mathrm{mM}$ additional dithiothreitol (Table III). Furthermore, the reduced enzyme activity in leukocytes from patients with $\mathrm{FH}$ persisted even after treatment with phosphatase or dithiothreitol.

Effects of plasmapheresis. Fig. 3 summarizes the results of plasmapheresis in six subjects. Serum total and LDL-cholesterol concentrations decreased $\sim 60 \%$ below basal in all individuals immediately after a 2 -h plasma exchange. Similar changes were noted for serum HDL cholesterol and triglycer-

Table II. Mononuclear Leukocyte HMG CoA Reductase Protein Concentration, Microsomal Activity, and Catalytic Efficiency in Normal Subjects and Patients with FH

\begin{tabular}{|c|c|c|c|c|}
\hline Diagnosis & $n$ & $\begin{array}{l}\text { HMG CoA reductase } \\
\text { protein concentration } \\
\text { (A) }\end{array}$ & $\begin{array}{l}\text { HMG CoA } \\
\text { reductase activity } \\
\text { (B) }\end{array}$ & $\begin{array}{l}\text { HMG CoA reductase } \\
\text { catalytic efficiency } \\
\text { (B/A) }\end{array}$ \\
\hline & & $\begin{array}{l}\mu \mathrm{g} \text { immunoreactive protein/mg } \\
\text { microsomal protein }\end{array}$ & $\begin{array}{l}\text { pmol/min/mg } \\
\text { microsomal protein }\end{array}$ & $\begin{array}{l}\text { pmol/min/mg } \\
\text { immunoreactive protein }\end{array}$ \\
\hline Normal & 31 & $39 \pm 4$ & $10.3 \pm 0.8$ & $313 \pm 34$ \\
\hline hFH & 13 & $47 \pm 4$ (NS) & $4.7 \pm 0.5^{*}$ & $92 \pm 9^{*}$ \\
\hline $\mathrm{HFH}$ & 12 & $86 \pm 11^{*}$ & $4.8 \pm 0.7^{\ddagger}$ & $65 \pm 10^{*}$ \\
\hline
\end{tabular}

$40 \mathrm{ml}$ of peripheral blood was obtained from 31 healthy, normocholesterolemic subjects, 13 patients with heterozygous $\mathrm{FH}$ (hFH) and 12 patients with homozygous FH (HFH) after an 11-14-h overnight fast. Mononuclear leukocytes were obtained after density gradient centrifugation over Histopaque 1077. Leukocyte microsomes were isolated and leukocyte microsomal HMG CoA reductase activity and enzyme protein concentration were measured in triplicate for each individual, as described in Methods. Data for HMG CoA reductase activity and enzyme protein concentration represent the mean of the average value obtained for each of the indicated number of individuals \pm SE. HMG CoA reductase catalytic efficiency was calculated by dividing enzyme activity by enzyme protein concentration for each individual. Values for HMG CoA reductase catalytic efficiency represent the means of the calculated catalytic efficiencies for the indicated number of individuals \pm SE. NS, Not significant. ${ }^{*} P<0.001$. $^{\ddagger} P<0.002$. 


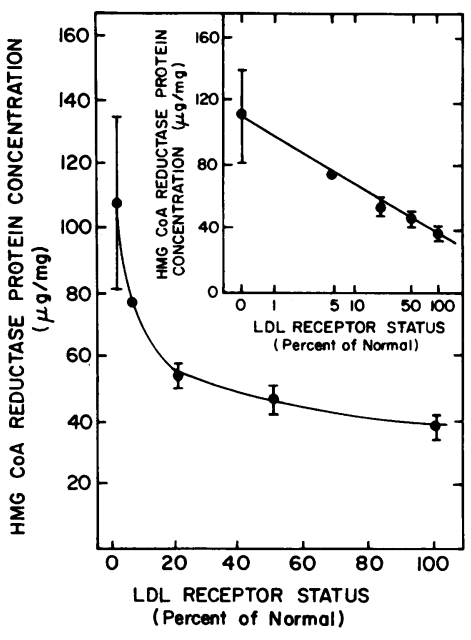

sess 100 and $50 \%$ of normal LDL-receptor activity, respectively. LDL-receptor status for 8 of the 12 homozygotes was determined in cultured fibroblasts. Four of these homozygous FH patients had $<2 \%$ of normal LDL-receptor activity, one patient had $5 \%$ of normal LDL-receptor activity, and three patients had between 15 and $25 \%$ of normal LDL-receptor activity (average $20 \%$ ). Shown is HMG CoA reductase protein concentration in freshly isolated mononuclear leukocytes as a function of the percentage of normal LDL-receptor status. (Inset) HMG CoA reductase protein concentration versus $\log _{10}$ LDL-receptor status.

ide concentrations. A linear relationship existed between LDL-receptor status and the change in mononuclear leukocyte HMG CoA reductase activity induced by plasmapheresis. In both normal subjects, the fall in serum lipids and lipoproteins was accompanied by approximately a twofold rise in HMG CoA reductase activity. In one patient with heterozygous $\mathrm{FH}$, enzyme activity also increased approximately twofold. In one receptor-defective homozygous $\mathrm{FH}$ patient with $\sim 20 \%$ of normal receptor activity, HMG CoA reductase activity in-

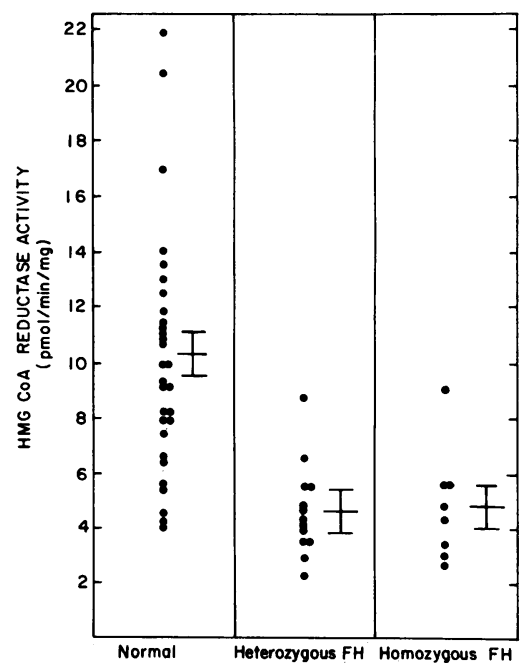

Figure 2. Freshly isolated mononuclear leukocyte HMG CoA reductase activity in normal subjects and patients with heterozygous or homozygous FH. $40 \mathrm{ml}$ of peripheral blood was obtained from 31 normocholesterolemic subjects, 13 patients with heterozygous $\mathrm{FH}$, and 8 patients with homozygous FH after an 11-14 h overnight fast. Mononuclear leukocytes were isolated by density gradient centrifugation over Histopaque 1077. Leukocyte microsomes were isolated and microsomal HMG CoA reductase activity was measured, as described in Methods. Shown are the average HMG CoA reductase activities for the individuals of each population. Error bars to the right of each set of data points represent the mean of the individual averages $\pm \mathrm{SE}$.
Table III. Decreased Leukocyte HMG CoA Reductase Activity in FH Is not Due to Enzyme Phosphorylation or Thiol-Disulfide Formation

\begin{tabular}{llc}
\hline & \multicolumn{2}{l}{ HMG CoA reductase activity } \\
\cline { 2 - 3 } Additions & $\begin{array}{l}\text { Normal subjects } \\
(n=11)\end{array}$ & $\begin{array}{l}\text { FH patients } \\
(n=7)\end{array}$ \\
\hline & pmol/min/mg microsomal protein \\
None & $9.8 \pm 1.4$ & $5.3 \pm 0.9$ \\
Phosphoprotein phosphatase & $8.9 \pm 1.9$ & $4.7 \pm 0.7$ \\
20 mM dithiothreitol & $8.4 \pm 0.7$ & $5.7 \pm 0.7$
\end{tabular}

Peripheral blood mononuclear leukocyte microsomes from 11 healthy, normocholesterolemic individuals and 7 patients with $\mathrm{FH}$ (150 mg) were incubated for $20 \mathrm{~min}$ at $37^{\circ} \mathrm{C}$ in $50 \mathrm{ml}$ of TEDK, 50 $\mathrm{ml}$ of TEDK containing $10 \mathrm{U}$ Escherichia coli alkaline phosphatase, or $50 \mathrm{ml}$ of TEDK containing $20 \mathrm{mM}$ dithiothreitol. HMG CoA reductase activity was measured in a second, 30-min incubation at $37^{\circ} \mathrm{C}$. Data represent the mean of the average HMG CoA reductase activities obtained for the indicated number of individuals \pm SE.

creased $\sim 60 \%$. In one of two LDL-receptor-negative patients, HMG CoA reductase activity remained low and was not stimulated by plasma exchange, whereas in the second receptor-negative subject, enzyme activity increased $\sim 50 \%$. This patient's genotype is unusual in that one abnormal gene codes for an absent fibroblast LDL receptor while the other codes for a single amino acid substitution in the cytoplasmic domain of the receptor, leading to a defect in internalization of the receptor-ligand complex (24). For the most part, therefore, the

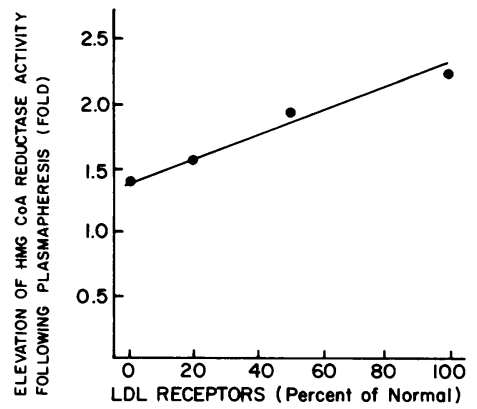

Figure 3. Effect of plasmapheresis on mononuclear leukocyte HMG CoA reductase activity in relation to LDL-receptor status. 40-ml blood samples were obtained from two normal individuals, one patient with heterozygous $\mathrm{FH}$, and three patients with homozygous FH immediately before and after a 2-h, 4 liter plasma exchange. Plasma

cholesterol concentrations decreased $\sim 60 \%$ for all individuals. Mononuclear leukocytes were isolated by density gradient centrifugation over Histopaque 1077. Leukocyte microsomes were isolated and microsomal HMG CoA reductase activity was measured, as described in Methods. Normal individuals and patients with heterozygous FH are presumed to possess 100 and $50 \%$ of normal LDL-receptor activity, respectively. The LDL-receptor status of cultured fibroblasts in the three homozygous FH patients were determined to be $15 \%$ (one patient) or $<2 \%$ (two patients) of normal. Shown is the ratio of postpheresis to prepheresis HMG CoA reductase activity as a function of the percent of normal LDL-receptor activity. Mean basal (prepheresis) HMG CoA reductase activity for each subject was 11.7 and 9.34 $\mathrm{pmol} / \mathrm{min}$ per $\mathrm{mg}$ for the normal individuals, $5.94 \mathrm{pmol} / \mathrm{min}$ per $\mathrm{mg}$ for the heterozygous $\mathrm{FH}$ patient, $3.38 \mathrm{pmol} / \mathrm{min}$ per $\mathrm{mg}$ for the homozygous FH patient with receptor-defective disease, and 4.63 and $4.79 \mathrm{pmol} / \mathrm{min}$ per $\mathrm{mg}$ for the two homozygous $\mathrm{FH}$ subjects with receptor-negative disease. 
magnitude of change in HMG CoA reductase activity in response to a rapid reduction in circulating lipoprotein cholesterol concentration was related to the LDL-receptor status of the subjects.

To determine the effect of plasmapheresis on mononuclear cell subpopulations, leukopheresis was conducted in a patient with heterozygous FH during a 4-liter plasma exchange. Leukopheresis was performed during the first and last liters of plasma exchange and the cells were separated into monocyteand lymphocyte-enriched populations. As shown in Fig. IV, plasmapheresis decreased the circulating LDL-cholesterol level $65 \%$. This was accompanied by over a threefold rise in monocyte HMG CoA reductase activity. In contrast, lymphocyte HMG CoA reductase activity remained essentially unchanged after plasmapheresis.

\section{Discussion}

The present data demonstrate that the microsomal enzyme activity and catalytic efficiency of $\mathrm{HMG}$ CoA reductase in freshly isolated mononuclear leukocytes are decreased in patients with FH. In contrast, the amount of immunoreactive enzyme protein is slightly above normal in heterozygous $\mathrm{FH}$ subjects and markedly increased in homozygous FH patients. The abnormal expression of microsomal enzyme activity and catalytic efficiency of HMG CoA reductase in FH cannot be explained by alterations in the phosphorylation state or thioldisulfide status of the enzyme, since the method for microsomal isolation fully activates the enzyme with respect to both regulatory mechanisms. Furthermore, neither in vitro addition of a protein phosphatase preparation nor addition of a considerable excess of the reducing agent dithiothreitol after microsomal isolation further stimulated enzyme activity. It remains to be determined whether the decrease in mononuclear leuko-

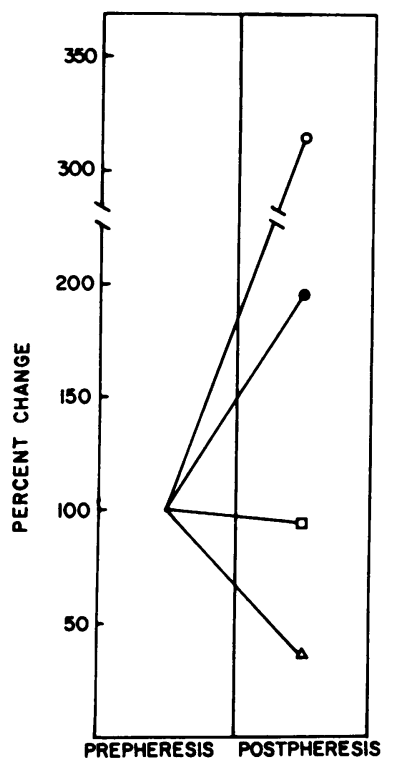

Figure 4. Stimulation of monocyte HMG CoA reductase activity by plasmapheresis. $40-\mathrm{ml}$ blood samples were obtained from a patient with heterozygous $\mathrm{FH}$ immediately before and after a 2-h, 4 liter plasma exchange. The initial (prepheresis) and final (postpheresis) units of blood to undergo plasma exchange were also subjected to leukopheresis. Mononuclear leukocyte, monocyteenriched, and lymphocyteenriched populations were isolated by density gradient centrifugation over Histopaque 1077. Leukocyte microsomes were isolated and $\mathrm{mi}-$ crosomal HMG CoA reductase was measured, as described in Methods. Shown is the percent change in plasma LDL cholesterol concentration (triangle), mononuclear leukocyte HMG CoA reductase activity (closed circle), monocyte HMG CoA reductase activity (open circle), and lymphocyte HMG CoA reductase activity (square) as a result of plasmapheresis. Mean basal (prepheresis) HMG CoA reductase activity was $5.94 \mathrm{pmol} / \mathrm{min}$ per $\mathrm{mg}$ for the mononuclear preparation, $2.46 \mathrm{pmol} / \mathrm{min}$ per $\mathrm{mg}$ for the monocyte-enriched fraction, and $10.1 \mathrm{pmol} / \mathrm{min}$ per $\mathrm{mg}$ for the lymphocyte-enriched fraction. cyte HMG CoA reductase catalytic efficiency in $\mathrm{FH}$ is due to an alteration in the enzyme molecule, perhaps leading to changes in the kinetic properties of HMG CoA reductase. Previous studies by Goldstein and Brown (25) using cultured fibroblasts indicated that the Michaelis constants for HMG CoA reductase were identical in normal and $\mathrm{FH}$ cells. It is conceivable, however, that a protein or other soluble factor exists in FH leukocytes that inhibits reductase activity without altering total enzyme concentration. It is also uncertain at this time whether the decrease in enzyme activity and catalytic efficiency observed here are unique to $\mathrm{FH}$ or whether similar changes in HMG CoA reductase occur in other disorders of lipoprotein metabolism.

Regardless of the precise mechanism for suppression of HMG CoA reductase activity in $\mathrm{FH}$, it is noteworthy that subjects with heterozygous FH and those with receptor-defective homozygous disease are able to show increased enzyme activity after rapid lowering of circulating cholesterol by plasmapheresis, whereas patients with LDL-receptor-negative homozygous FH exhibit little or no change in HMG CoA reductase activity after plasmapheresis. These results, and our previous studies (10), indicate that the effect of plasma exchange on mononuclear leukocyte HMG CoA reductase activity is due principally, if not entirely, to stimulation of the monocyte enzyme. The stimulation of HMG CoA reductase activity and, presumably, cholesterol biosynthesis, by plasmapheresis may provide insight into the rapid restoration of circulating cholesterol levels after this procedure in patients with $\mathrm{FH}(26-28)$. By removing large amounts of serum lipoprotein, plasmapheresis may derepress HMG CoA reductase in white cells and other tissues and, consequently, stimulate whole body cholesterolgenesis. Such an effect has been described in rats undergoing plasma exchange (29). Thus, both increased de novo cholesterol formation and decreased receptor-mediated uptake of lipoprotein cholesterol may mediate the restoration of circulating lipid levels after plasmapheresis in FH patients.

The apparent suppression of basal mononuclear HMG CoA reductase activity in $\mathrm{FH}$ may seem at variance with the results obtained in numerous experiments with cultured human cells $(6,7)$. Indeed, it is postulated that most normal cells derive the majority of their cholesterol from receptor-mediated endocytosis of lipoprotein cholesterol, rather than from receptor-independent endocytosis or from intracellular synthesis (1). Moreover, this model suggests that lipoprotein cholesterol, or a metabolite of cholesterol, acts to maintain HMG CoA reductase in a chronically suppressed state, in part by inhibiting transcription of the HMG CoA reductase gene (1). By this mechanism, therefore, changes in cellular demand for cholesterol would be met principally by increasing or decreasing availability of LDL receptors, rather than by altering $H M G$ CoA reductase activity or protein (2). Studies with fibroblasts maintained in culture for up to $72 \mathrm{~h}$ indicate that, in heterozygous FH, only approximately half the normal number of LDL receptors are present (7). This number is still sufficient, however, to provide enough cholesterol to meet the metabolic requirements of the cell and to maintain HMG CoA reductase in a repressed state. In contrast, cultured fibroblasts from patients with LDL-receptor-negative homozygous disease are forced to derive the bulk of their cholesterol from endogenous biosynthesis (1). Consequently, HMG CoA reductase activity in these cells is abnormally high $(3,6,7)$. In this regard, it has been reported that the activity of HMG CoA reductase is severalfold 
greater than normal in cultured fibroblasts obtained from patients with homozygous FH, while enzyme activity in cells from heterozygous patients is normal (3).

Several aspects of these classic experiments, however, require careful interpretation. First, in these studies, HMG CoA reductase protein concentration was not measured directly but was inferred from changes in the activity of the fully dephosphorylated enzyme (3). Thus the reported differences in enzyme activity in FH versus normal cells could have been due either to a change in HMG CoA reductase protein concentration or catalytic efficiency, independent of the effects of phosphorylation. Indeed, our study is the first, to our knowledge, to quantitate immunoreactive $\mathrm{HMG} \mathrm{CoA}$ reductase protein levels in cells from FH subjects and to relate enzyme protein concentration to microsomal enzyme activity. Second, experiments in which reductase activity in cultured FH fibroblasts was reported to be increased were conducted after incubation of these cells for at least $24 \mathrm{~h}$ in media containing a small percentage (usually $10 \%$ ) of fetal calf serum $(3,7)$. While the concentration of lipoprotein cholesterol in such media would be sufficient to meet cellular cholesterol needs in normal fibroblasts, it is appreciably less than the extracellular cholesterol concentration to which homozygous FH cells are chronically exposed in vivo. Thus, since fibroblasts from FH homozygotes cannot efficiently internalize lipoprotein cholesterol, longterm incubation of cells in dilute serum would maximally derepress HMG CoA reductase synthesis and stimulate intracellular cholesterolgenesis. Consistent with this prediction is the finding that, in normal cultured cells transferred from lipoprotein-replete to lipoprotein-deficient media, HMG CoA reductase synthesis is derepressed to a level of enzyme activity similar to that observed in FH homozygous cells cultured in dilute serum or in lipoprotein-deficient medium (7). Finally, many investigators have reported that the high levels of HMG CoA reductase activity are not altered in cultured cells from homozygous FH patients by short-term exposure to concentrations of LDL cholesterol that markedly inhibit the enzyme in normal cells $(3,6,7,30,31)$. In virtually all these experiments, however, medium concentrations of lipoprotein cholesterol did not exceed $200 \mathrm{mg} / \mathrm{dl}$. This concentration is substantially below the level of circulating LDL cholesterol present in the vast majority of untreated patients with heterozygous or homozygous disease (1). Thus, an LDL-receptor-independent process for cellular uptake of circulating cholesterol, operating at chronically high ambient levels of cholesterol, would have been missed by the experimental conditions used with cultured cells. Moreover, our results are consistent with studies indicating that intestinal (32) and hepatic (33) HMG CoA reductase activities measured in freshly isolated tissues, as well as total body cholesterol synthesis (34-36), are usually normal or decreased in adults with FH.

If it is assumed that the suppression of HMG CoA reductase activity in mononuclear leukocytes and other cells of FH patients is due in some way to elevated serum cholesterol concentrations, then there are several mechanisms other than receptor-mediated uptake of LDL that could account for our findings. For example, receptors for cholesterol-enriched remnant particles of VLDL catabolism are present on monocytes and certain other cells from both normal individuals and patients with FH (37-40). Remnant lipoproteins may be increased in FH and are capable of mediating inhibition of
HMG CoA reductase (37). In addition, a low affinity, nonreceptor-mediated (scavenger) pathway exists in monocytes and other cells for uptake of lipoprotein cholesterol (8) and, presumably, for suppression of cellular cholesterol biosynthesis. Finally, cultured fibroblasts from normal and homozygous FH subjects can incorporate exogenous free cholesterol into their membranes by physical exchange of lipid with LDL (41). This cholesterol is available for intracellular esterification and, perhaps, for down-regulation of HMG CoA reductase. Whether such exchange can occur in vivo in the absence of net cellular cholesterol transport is unknown. It is also possible that lipoprotein cholesterol, upon entry into cells by routes independent of the classical LDL-receptor pathway, is processed in such ways as to exert preferential suppression of preexisting HMG CoA reductase molecules, relative to newly synthesized enzyme. The fate of lipoprotein cholesterol in $\mathrm{FH}$ versus normal cells is not well understood, but the possibility of abnormalities in metabolic comparmentalization and/or metabolism of cholesterol in FH is intriguing. Indeed, studies of the regulation of $\mathrm{HMG} \mathrm{CoA}$ reductase in liver from ancephalic fetuses (42) or patients with homozygous FH (43) indicate that metabolic channeling of cholesterol may differ from normal, such that the activity and protein concentration of $\mathrm{HMG} \mathrm{CoA}$ reductase in these conditions may not be coordinately controlled.

Finally, recent evidence suggests that current methods used to estimate $\mathrm{LDL}$ receptor activity in cultured fibroblasts may not accurately reflect receptor status of other cells in vivo. Hoeg and co-workers have reported that receptors for LDL on fibroblasts and liver are genetically distinct, and that some patients with homozygous FH show significant and saturable binding of LDL to liver cells, while expressing essentially no LDL-receptor activity in cultured fibroblasts (44). Differences in cholesterol-mediated inhibition of LDL-receptor expression and $\mathrm{HMG}$ CoA reductase activity have also been noted in monocyte-derived macrophages, compared with cultured fibroblasts. Tabas et al. (45) have shown that in macrophages, but not fibroblasts, aceyl coenzyme A cholesterol aceyl transferase may compete for a regulatory pool of intracellular cholesterol, leading to diminished down-regulation of receptor function and reductase activity.

In conclusion, in vivo suppression of $\mathrm{HMG}$ CoA reductase activity and catalytic efficiency in mononuclear leukocytes and perhaps other cells in $\mathrm{FH}$, and the stimulation of the mononuclear leukocyte enzyme after plasmapheresis in patients with functional LDL receptors, clearly implies that the in vivo activity of $\mathrm{HMG}$ CoA reductase is in part determined by the concentration of circulating lipoprotein cholesterol. However, the fact that HMG CoA reductase activity is low even in leukocytes isolated from patients considered LDL-receptor-negative suggests that sufficient cholesterol is internalized by these cells to influence cholesterol biosynthesis. Why cells from so-called receptor-negative homozygotes have decreased HMG CoA reductase activity and catalytic efficiency despite elevated immunoreactive enzyme protein concentrations is unknown. Whatever the mechanisms, these studies reveal a previously unrecognized abnormality in the regulation of cellular cholesterol metabolism in FH that is independent of the defect in LDL receptor function and that may provide additional insight into the pathogenesis of this genetic disorder. 


\section{Acknowledgments}

We are indebted to Drs. Vera Miles and J. Alick Little (University of Toronto, Canada), and to Dr. John Pearson (Vanderbilt University, Nashville, TN), for the opportunity to study their patients. The nursing and dietary staff of the Clinical Research Center, Shands Hospital provided excellent care of patients studied at the University of Florida. Finally, we thank Yvonne J. Greene for expert technical assistance and Penny Moeller for typing the manuscript.

This work was supported by grant HL-3250 from National Institutes of Health (NIH), Clinical Research Grant 6-409 from the March of Dimes Birth Defects Foundation, grant CA-40495 from the National Cancer Institute, grant IN-62W, project ACS-83-069, from the American Cancer Society, and by a grant from the Florida Citrus Commission. Dr. Stacpoole is the recipient of a Research Career Development Award from the NIH. Dr. Harwood was the recipient of a New Investigator Research Award from the National Cancer Institute.

\section{References}

1. Brown, M. S., and J. L. Goldstein. 1986. A receptor-mediated pathway for cholesterol homeostasis. Science (Wash. DC). 232:34-47.

2. Brown, M. S., P. T. Kovanen, and J. L. Goldstein. 1981. Regulation of plasma cholesterol by lipoprotein receptors. Science (Wash. DC). 212:682-635.

3. Brown, M. S., S. E. Dana, and J. L. Goldstein. 1974. Regulation of 3-hydroxy-3-methylglutaryl coenzyme A reductase activity in cultured human fibroblasts. Comparison of cells from a normal subject and from a patient with homozygous familial hypercholesterolemia. $J$. Biol. Chem. 249:789-796.

4. Brown, M. S., and J. Goldstein. 1981. Lowering plasma cholesterol by raising LDL receptors. $N$ Engl J Med. 305:515-517.

5. Havel, R. J., J. Goldstein, and M. S. Brown. 1980. Lipoproteins and lipid transport. In Metabolic Control and Disease. P. K. Bondy and L. E. Rosenberg, editors. 8th ed. W. B. Saunders Co., Philadelphia. 393-494.

6. Brown, M. S., and J. L. Goldstein. 1974. Expression of the familial hypercholesterolemia gene in heterozygotes: mechanism for a dominant disorder in man. Science (Wash. DC). 185:61-63.

7. Ho, Y. K., J. R. Faust, D. W. Bilheimer, M. S. Brown, and J. L. Goldstein. 1977. Regulation of cholesterol synthesis by low density lipoprotein in isolated human lymphocytes. Comparison of cells from normal subjects and patients with homozygous familial hypercholesterolemia and abetalipoproteinemia. J. Exp. Med. 145:1531-1549.

8. Harwood, H. J., Jr., M. Schneider, and P. W. Stacpoole. 1984. Measurement of human leukocyte microsomal HMG-CoA reductase activity. J. Lipid Res. 25:967-978.

9. Harwood, H. J., Jr., I. M. Alvarez, Y. J. Greene, G. C. Ness, and P. W. Stacpoole. 1987. Development of a noncompetitive, solid phase, bridged biotin-avidin enzyme immunoassay for measurement of human leukocyte microsomal HMG-CoA reductase protein concentration. J. Lipid Res. 28:292-304.

10. Harwood, H. J., Jr., D. Bridge, and P. W. Stacpoole. 1987. In vivo regulation of human mononuclear leukocyte 3-hydroxy-3-methylglutaryl coenzyme A reductase. Studies in normal subjects. J. Clin. Invest. 79:1125-1132.

11. Rodwell, V. W., J. L. Nordstrom, and J. J. Mitschelen. 1976. Regulation of HMG-CoA reductase. Adv. Lipid Res. 14:1-74.

12. Rifkind, B. M., and P. Segal. 1983. Lipid research clinics program reference values for hyperlipidemia and hypolipidemia. J. Am. Med. Assoc. 250:869-872.

13. Ness, G. C., C. E. Sample, M. Smith, and D. C. Eichler. 1986. Characteristics of rat liver microsomal 3-hydroxy-3-methylglutaryl coenzyme A reductase. Biochem. J. 233:167-172.

14. Stacpoole, P. W., H. J. Harwood, Jr., and C. E. Vernado. 1983.
Regulation of rat liver hydroxymethylglutaryl coenzyme A reductase by a new class of noncompetitive inhibitors. Effects of dichloroacetate and related carboxylic acids on enzyme activity. $J$. Clin. Invest. 72:1575-1585.

15. Harwood, H. J., Jr., M. Schneider, and P. W. Stacpoole. 1984. Measurement of human leukocyte microsomal HMG-CoA reductase activity. J. Lipid Res. 25:967-978.

16. Harwood, H. J., Jr., M. Schneider, and P. W. Stacpoole. 1984. Regulation of human leukocyte microsomal hydroxymethylglutaryl CoA reductase activity by a phosphorylation and dephosphorylation mechanism. Biochim. Biophys. Acta. 805:245-251.

17. Bradford, M. M. 1976. A rapid and sensitive method for the quantitation of microgram quantities of protein using the principle of protein-dye binding. Anal. Biochem. 72:248-254.

18. National Heart, Lung and Blood Institute. 1974. Lipid Research Clinics Manual I. Department of Health, Education and Welfare, National Institutes of Health, Bethesda, MD. Publication No. 75:628.74.

19. Friedewald, W. T., R. I. Levy, and D. S. Fredrickson. 1979. Estimation of the concentration of low-density lipoprotein cholesterol in plasma, without use of the preparative ultracentrifuge. Clin. Chem. 7:397-402.

20. Young, N. L., and V. W. Rodwell. 1977. Regulation of hydroxymethylglutaryl-CoA reductase in rat leukocytes. J. Lipid Res. 18:572-581.

21. Goldfarb, S., and H. C. Pitot. 1972. Stimulatory effect of dietary lipid and cholestyramine on hepatic HMG CoA reductase. $J$. Lipid Res. 13:797-801.

22. Kennelly, P. J., and V. W. Rodwell. 1985. Regulation of 3-hydroxy-3-methylglutaryl coenzyme A reductase by reversible phosphorylation-dephosphorylation. J. Lipid Res. 26:903-914.

23. Roitleman, J., and I. Shechter. 1984. Regulation of rat liver 3-hydroxy-3-methylglutaryl coenzyme A reductase. Evidence for thiol-dependent allosteric modulation of enzyme activity. J. Biol. Chem. 259:870-877.

24. Brown, M. S., and J. L. Goldstein. 1976. Analysis of a mutant strain of human fibroblasts with a defect in the internalization of receptor-bound low density lipoprotein. Cell. 9:663-674.

25. Goldstein, J. L., and M. S. Brown. 1973. Familial hypercholesterolemia: identification of a defect in the regulation of 3-hydroxy-3methylglutaryl coenzyme A reductase activity associated with overproduction of cholesterol. Proc. Natl. Acad. Sci. USA. 70:2804-2808.

26. Thompson, G. R., Lowenthal, R., and N. B. Myant. 1975. Plasma exchange in the management of homozygous familial hypercholesterolemia. Lancet i:1028-11.

27. Lupien, P. J., S. Moorjani, and J. Awad. 1976. A new approach to the management of familial hypercholesterolemia: removal of plasma-cholesterol based on the principal of affinity chromatography. Lancet. ii: 1261-1265.

28. Apstein, C. S., D. B. Zilversmit, R. S. Lees, and P. K. George. 1978. Effect of intensive plasmapheresis on the plasma cholesterol concentration in familial hypercholesterolemia. Atherosclerosis. 31:105-115.

29. Takeuchi, N., and Y. Yamamura. 1972. The effect of plasmapheresis on cholesterol synthesis in the rat: relationship to protein synthesis. J. Lab. Clin. Med. 79:801-813.

30. Higgsin, M. J. P., and D. J. Galton. 1977. The regulation of sterol biosynthesis in leukocytes of subjects with familial hypercholesterolemia. Eur. J. Clin. Invest. 7:301-305.

31. Reichl, D., N. B. Myant, M. S. Brown, and J. L. Goldstein. 1978. Biologically active low density lipoprotein in human peripheral lymph. J. Clin. Invest. 61:64-71.

32. Freeman, M. L., W. F. Prigge, D. B. Hunninghake, W. C. Duane, and R. L. Gebhard. 1986. Intestinal HMG CoA reductase is low in hypercholesterolemic patients and its activity is altered by drugs. Clin. Res. 34:629A. (Abstr.) 
33. Nichlau, G., S. Shefer, G. Salen, and E. H. Mosbach. 1974. Determination of hepatic 3-hydroxy-3-methylglutaryl CoA reductase activity in man. J. Lipid Res. 15:94-98.

34. Miettinen, T. A. 1970. Detection of changes in human cholesterol metabolism. Ann. Clin. Res. 2:300-320.

35. Langer, T., W. Strober, and R. I. Levy. 1972. The metabolism of low density lipoprotein in familial type II hyperlipoproteinemia. $J$. Clin. Invest. 5:1528-1536.

36. Samuel, P., and W. Perl. 1970. Long-term decay of serum cholesterol radioactivity: body cholesterol metabolism in normals and in patients with hypercholesterolemia and atherosclerosis. J. Clin. Invest. 49:346-357.

37. Brown, M. S., and J. L. Goldstein. 1983. Lipoprotein metabolism in the macrophage; implications for cholesterol deposition in atherosclerosis. Annu. Rev. Biochem. 52:223-261.

38. Gianturco, S. H., F. B. Brown, A. M. Gotto, Jr., and W. A. Bradley. 1982. Receptor-mediate uptake of hypertriglyceridemic very low density lipoproteins by normal human fibroblasts. J. Lipid Res. 23:984-993.

39. Gianturco, S. H., W. A. Bradley, A. M. Gotto, Jr., J. D. Morrisett, and D. L. Peavy. 1982. Hypertriglyceridemic very low density lipoproteins induce triglyceride synthesis and accumulation in mouse peritoneal macrophages. J. Clin. Invest. 70:168-178.

40. Gianturco, S. H., A. M. Gotto, Jr., S.-L. C. Hwang, J. B. Karlin, A. A. Y. Lin, S. C. Prasad, and W. A. Bradlwy. 1983. Apoprotein E mediates uptake of $\mathrm{S}_{\mathrm{f}} 00-400$ hypertriglyceridemic very low density lipoproteins by the low density lipoprotein receptor pathway in normal human fibroblasts. J. Biol. Chem. 258:4526-4533.

41. Slotte, J. P., S. Ekman, and S. Bjokerud. 1984. Uptake and esterification of exogenous cholesterol by low-density-lipoprotein-receptor-negative human fibroblasts in culture. Biochem. J. 222:821824.

42. Carr, B. R., W. E. Rainey, and J. L. Mason. 1985. 3-Hydroxy3-methylglutaryl coenzyme $A$ reductase in anencephalic and normal human fetal liver. J. Clin. Invest. 76:1946-1949.

43. Edge, S. B., J. M. Hoeg, T. Triche, P. D. Schneider, and H. B. Brewer, Jr. 1986. Cultured human hepatocytes. Evidence for metabolism of low density lipoproteins by a pathway independent of the classical low density lipoprotein receptor. J. Biol. Chem. 261:3800 3806.

44. Hoeg, J. M., S. J. Demosky, Jr., K. J. Lackner, J. C. Osborne, Jr., C. Oliver, and H. B. Brewer, Jr. 1986. The expressed human hepatic receptor for low-density lipoproteins differs from the fibroblast low density lipoprotein receptor. Biochim. Biophys. Acta. 876:13-21.

45. Tabas, I., D. A. Weiland, and A. R. Tall. 1986. Inhibitio of acyl coenzyme A: cholesterol acyl transferase in $\mathbf{J} 774$ macrophages enhances down-regulation of the low density lipoprotein receptor and 3-hydroxy-3-methylglutaryl-coenzyme A reductase and prevents low density lipoprotein-induced cholesterol accumulation. J. Biol. Chem. 261:3147-3155. 